\title{
Editorial
}

\section{Editing and curation}

Contemporary Political Theory (2016) 15, 1-15. doi:10.1057/cpt.2015.69

The space for writing this editorial, as with all the other material published in Contemporary Political Theory over the years, was made possible by the vision, dedication and years of hard work of CPT's founding editors, Raia Prokhovnik and Gary Browning. When Terrell Carver and I took over as editors from Gary and Raia more than five years ago, we initially discussed the possibility of writing an editorial for the first issue with our names on the masthead - Issue 9.4, November 2010. However, at the time we had a host of other items to worry about; Issue 9.4, like the four issues that followed it, contained content edited by the former editors; and above all, our main editorial intention was to carry on and build upon the work of Gary and Raia, not to take $C P T$ in a radically different direction. In a sense then, we felt we had nothing to say at the time - or, at the least, nothing we needed to say in words. We wanted our editorial work itself to speak to readers and authors.

Moreover, had we editorialized back then, it was not at all clear to us that we would say anything different than was said in the first editorial by Browning, Prokhovnik and Kimberly Hutchings. In Issue 1.1, they opened the journal with these words: 'Contemporary Political Theory is a distinctive new journal that aims to reflect the breadth of political theory and to serve as a lively forum for articles that express the wide range of the subject, and whose common denominator will be the high quality of their argument'. In 2010, the only edit needed was to remove 'new'. And over the years we have also shared that original editorial's vision of political theory as a field of inquiry:

Political theory is a rigorous and unsettling discipline that attracts a diversity of practitioners who, in drawing upon different traditions and developing individual ways of theorising, account for the character of politics and evaluate political practice in distinct, profound and disturbing ways. Political theory remains the serious, heterogeneous subject that it has been in the recent and remote pasts and Contemporary Political Theory aims to publish articles that contribute to its practice of dialogue and debate, and thereby to demonstrate the strength and vitality of the subject. (Browning et al., 2002, p. 1)

Terrell and I did update the journal's 'aims and scope' to underscore our commitment to political theory not just as a field or discipline, but as a project that travels across a

(C) 2016 Macmillan Publishers Ltd. 1470-8914 Contemporary Political Theory Vol. 15, 1, 1-15 
wide variety of disciplinary, subfield and nation-state borders. Nonetheless, rather than repeat the words of the previous editors, we got on with the work of running the journal.

I am writing this editorial essay today to take stock of the past five years and then to announce the next editorial transition in CPT's 14-year history. Since Terrell and I became co-editors of the journal in summer 2010, I have been the sole editor in charge of submissions. Over that time I have learned a lot: about the nuts and bolts of the submissions process, about authors' and reviewers' broad and dramatically divergent perceptions of that process, and about the utterly distinct and often completely conflictual visions and practices of the editorial process by journal editors themselves.

I have learned, first, that there is no shared understanding about how journal submissions are actually run; perhaps this should come as no big surprise since only a small percentage of scholars get to peek behind a journal's 'confidentiality curtain'. Most journals, moreover, remain opaque about what their editorial submissions principles and practices look like, thereby exacerbating the general problem. Put simply: we rarely talk about these issues forthrightly, despite their absolute centrality to the work we do. Second, there is no consensus among editors about how a submissions process should be run. For me at least, this fact was surprising, as I had thought that my latent and nascent sense of both procedures and ethos would be shared by most. Over the years in talking to other editors, and in engaging in sometimes extended dialogues with reviewers and authors, it has grown increasingly clear to me that the way I have run submissions at $C P T$ is by no means the way that everyone runs submissions everywhere.

Of course there is no single way to run journal submissions, and the last thing I intend here is to suggest that my way is the best or only way. However, I do want to claim that we should be talking more about how submissions processes are actually run, and that we ought to create more dialogue about the divergent visions of editorial practices. The fact that confidentiality is essential to the peer review process does not mean that we cannot talk about how the process works. And the fact that submissions editors have the authority to run the submissions process in the way they see fit - a principle I would surely affirm - does not mean that the question of how best to run submissions cannot be subject to debate. Authors, reviewers, editors, prospective future editors - everyone has a stake in how a journal is run, even if not everyone has a say in the specific management of any particular journal. I would like this editorial to serve as an opening to further and much more wide-ranging discussion. I would like to see a future in which authors and reviewers have a far clearer sense of both the day-to-day submissions practices of various journals and the submissions philosophy of editors.

In the spirit of opening that conversation, in this editorial essay I would like to do something seemingly banal, but which I hope might also be somewhat radical namely, to describe directly and succinctly the editorial process at CPT as I have 
run submissions. This account will then serve as a basis from which I can articulate my own submissions philosophy as it emerged over that time; that approach depends upon marking and upholding an always-fuzzy distinction between editing a journal and curating a journal. ${ }^{1}$ (If you already know, or have no interest in, how submissions are run, you may want to skip to the next section.) Finally, I will close by making an important announcement about our new editorial lineup and the structure of journal submissions for the future.

\section{Article Editorial Practices at $C P T$}

\section{Journal structure and 'peer review'}

When I started as submissions editor I gave myself one primary charge: to uphold a fair and rigorous double-blind peer review process. The idea sounded simple in my head, but it turned out in practice to require a lot more groundwork than I would have ever imagined. The problem became clear to me immediately, since once my name was put on the $C P T$ website, I started getting at least two or three requests per week for special issues or symposia. This required me to take a step back and consider the basic structure of a journal.

Readers all know that it is now standard across the humanities and social sciences to distinguish between 'peer-reviewed journals' and edited volumes, encyclopedias, and on down the line to occasional essays, works in the popular press and so on. Certainly the primary distinction, between journals that are peer reviewed and all the other outlets that are not, matters. But there's a terrible secret that almost everyone knows but no one wants to talk about: not everything published in a peer-reviewed journal is peer-reviewed work. Anyone who has participated in a guest-edited special issue, or special symposium, has a sense of this, and anyone who has edited such a project knows it well. The logic is not hard to reconstruct. Most top journals in political theory and allied fields have extremely high rejection rates, but I will confine myself to a discussion of $C P T$. Over my time as submissions editor our rejection rate has oscillated between 85 and 90 per cent. This fact raises an obvious question: given that we reject eight or nine out of every ten submissions, how on earth could we ever publish, as peer-reviewed articles, a collection of four to six papers presented at a conference, for example? The odds that a group of six papers, all on the same topic, will all get accepted at the same time are, quite literally, 1 in a million - that is, the statistical chances are 0.00001 per cent.

Therefore, I realized that if I wanted to uphold the very high standards of blind peer review that I believed in, I had to be pellucidly clear about what material in the journal was subject to peer review, and what was not. Thus, Terrell and I internally restructured the journal by forming an ethical firewall to separate 'Articles' and 'everything else'. My job as submissions editor was to focus on articles, which would 
all be subject to the same rigorous blind review process. This first architectural move gave us the freedom to be creative with what we did in the 'everything else' category. With the help of Lisa Disch, we built our new 'Critical Exchanges', and we sent out a huge number of email responses explaining that $C P T$ no longer publishes any 'special issues' or symposia, but that we are open and excited to do that same kind of work through our CE's. Significantly, we made it clear to everyone: CE's are not, and have never been peer reviewed. This gives the $\mathrm{CE}$ editor enormous flexibility: to solicit manuscripts on important, timely, and relevant topics; to reach out to top names in the field and to junior scholars to foster dialogue; to coordinate exchanges between particular people, from particular fields and locations and backgrounds. We wanted to affirm the importance of the sort of work often published in symposia, while also being transparent with everyone (that is, prospective article authors and prospective CE participants) about what counted as 'peer reviewed' and what did not. I was then free to implement specific standards, principles and practices for peer review.

\section{'Fit' and the 'contemporary'}

Regardless of which material is potentially subject to peer review (in CPT's case, all articles) before implementing such a review process there comes the prior decision of which articles go out for external review and which do not. The category of those that do not go out for external review can loosely be broken down into two subcategories: (i) those that are rejected because they simply do not fit the topic, aims, or approach of the journal, and; (ii) those that do fit, but which clearly, and from the outset, do not meet the standards of publication in the journal and which, therefore, would have close to a zero per cent chance of success in the external review process. $^{2}$

In the spirit of $C P T$ as a broad, varied, and we might say vociferously interdisciplinary journal, I have been extremely hesitant to reject manuscripts because of their lack of 'fit'. Of the approximately 750 manuscripts reviewed during my tenure, my estimate is that less than a dozen were rejected because of fit, and many of those were literally articles for another discipline entirely - for example, a piece in physics or a piece in genetics. At the start of my editorship, I frequently received emails asking for clarification about what the 'contemporary' meant in $C P T$, and to what extent it circumscribed what could 'fit' in the journal. I answered by explaining that 'contemporary' does not designate a period that would exclude the treatment of some authors or figures in the history of political thought. Rather, $C P T$ is open to work on authors from any time or place; hence a piece on Heraclitus is just as likely to 'fit' with our aims and scope as a piece on Badiou. We are open to and interested in work that uses the history and thought of any time or place to speak to the contemporary world (particularly its theory and politics) in much the same way that Foucault spoke of doing 'the history of the present'. Therefore, it is true that a 
piece on Plato that tries only to reconstruct historical context solely in order to correct the historical record would probably not work well at $C P T$, but neither would a piece on Arendt or Rawls that does the same. Hence, there is a meaning to 'contemporary' in Contemporary Political Theory, but I must underscore this point: I almost never invoked an idea of 'the contemporary' in order to draw a line between what was appropriate and inappropriate for $C P T$. Indeed, there were only one or two occasions when I rejected a piece because its narrow and exclusively contextualist focus on a figure in the past made it inappropriate for $C P T$.

More often, but still quite rarely (only a handful of times), a piece was rejected because it very explicitly and self-reflectively sited itself in, and only in, specific and narrow debates within International Relations (IR). If the stakes of a piece were only recognizable to self-avowed IR scholars, then the piece did not fit at $C P T$ (though surely a differently framed, but quite similar, piece could do so - which is what I told the authors of those pieces). Overall, however, 'fit' was never a meaningful metric used to judge manuscripts, and almost every manuscript submitted made it past the 'fit' question to be judged on its own merits as a potential contribution to the field, broadly conceived.

\section{Internal review}

Turning then to the wider category of those manuscripts that do not go out for external review, let me say first that these are often named 'desk rejects,' but at $C P T$ we refer to these as pieces that have been rejected after 'internal review'. This semantic distinction is meant to emphasize that while internal review is not a full, double-blind review process, it is still a review process, in that the piece is read completely and closely by one or more editors or associate editors and a short report justifying the internal rejection is drawn up.

My aim has always been to minimize internal rejections. The internal rejection rate has a significant impact on the very nature and meaning of the external blind review process. I will say more about this below, but this is the main reason why I feel that the internal reject rate should not be allowed to go too high: at a certain point, a very high internal reject rate subverts the integrity of the peer review process. Here, however, I should also specify that I would strenuously reject the idea of bringing internal rejects to zero. In my time as editor our internal rejection rate has gradually gone up, just as our number of submissions has gone up. When I first took over we were receiving around 100 submissions per year, and our internal reject rate was 15-20 per cent. Last year we received closer to 200 submissions and our internal reject rate was 25-30 per cent. Note: this means that in 2010 we sent out approximately 80 manuscripts for external review, and in 2014 we sent out almost twice that number. In doubling the number of manuscripts sent out we also double the number of reviews we need to request (every manuscript sent out for external review 
probably requires, on average, four requests for external review). These numbers explain my position on trying to reduce the internal reject rate below a certain threshold: the demand on reviewers' time is enormous, and it is simply untenable and unprofessional to add to the reviewers' burden requests to review manuscripts that, in the judgement of the editors, simply have no meaningful chance of success. Rule number one of being a submissions editor: cherish thy reviewers. ${ }^{3}$ The task of running a journal is quite simply impossible without them. Thus, while I find it essential to keep the internal reject rate low, it is also important and necessary to the healthy functioning of the journal to reject a significant number of manuscripts internally.

Our goal at $C P T$ has always been for our internal rejects to be honest and forthright, to explain to the author directly why the piece does not reach the standards necessary to go out for external review, in a way that we hope can be helpful for that author in the long run. There are an infinite number of reasons why a piece might not be strong enough to make it past internal review; hence it would be impossible to catalog them here.

However, I would like to mention briefly one important distinguishing element of the overall review process, one that frequently plays a role in internal review. We have an abiding goal to publish work that is broad, which speaks forcefully to the widest possible expanse of our audience - an audience that crosses all fields in political theory and reaches to many other fields outside of politics and political science, an audience that draws from a great diversity of textual sources, analytic and conceptual tools, and historical and theoretical approaches. We never intentionally publish work that is only accessible to, or of interest for, specialists. We want every article we publish to speak both to those readers who know the sources and internal debates well and to those readers who are encountering the thinkers for the first time or who were only dimly aware of the importance of such debates. For these reasons, we insist that no matter what figures they are addressing, authors must always broaden out rather than focus in. Rather than revolving around one thinker, we prefer manuscripts that center on themes or problematiques. Those that do focus on one thinker (or two) must make that figure speak to the wider $C P T$ audience, must show how the writing connects to the broad-ranging issues, topics and debates that animate the field of contemporary theory. ${ }^{4}$

\section{External review}

In some ways, given all the earlier constitutive conditions, this is the easiest part of the process. First, to spell out some points that most readers probably already assume: we only file and process anonymous manuscripts (the review process cannot begin without an anonymous manuscript); we only circulate manuscripts that are both nonauthor-identifying and which have been digitally anonymized (no identifying info in 
the metadata of the PDF); and we only circulate to authors anonymous and anonymized PDFs of reviews. ${ }^{5}$

For the vast majority of pieces sent out for external review we get two reviews, but because of extenuating circumstances there are occasions when we get one review, and occasions when we get three. We never R\&R or Accept a piece on the basis of one review, but in cases where a second review is not forthcoming, and when time is of the essence, we will sometimes reject based on a single clear, thorough, and objectively fair review. In my time as submissions editor we gave an 'Accept with Revision' decision on the first round of review a total of one time. All other pieces that were accepted reached that stage only after going through a round of R\&R. Rejected manuscripts may not, under any circumstances, be resubmitted. All R\&R'd manuscripts are subject to a second, full round of review. Our standard practice with $R \& R$ 'd manuscripts is to send the revised manuscript to the same original two reviewers, but there are times when the fairest course of action is to deviate from this general principle. We also have a general policy (as stated in the 'Instructions for authors') that we only allow one round of R\&R; hence, resubmitted pieces are subject to a reject or accept decision. I should note, however, that there have been two or three times when this general rule was broken - times when it seemed to me that the only fair thing to do was to offer an author a second round of R\&R.

We ask reviewers to make a confidential decision recommendation for the benefit of the editors, and this includes four categories: (A) accept with minor revisions (hardly ever chosen), (B) accept with significant revisions, (C) revise and resubmit and (D) reject. We then ask reviewers to explain their decision and to offer detailed constructive criticism, all in anonymous comments for the author. Reviewers are also free to provide other confidential comments to the editors, but we do not encourage reviewers in this direction. As an editor, what I need most of all from a reviewer is the text of a genuine and generous engagement with the manuscript that I can share with the author; thus, detailed confidential comments are not that useful - unless of course there are special circumstances that need to be explained. One point worth clarifying here: we do not share with authors the decision recommendation of reviewers, and this is for the very important reason that reviews themselves (and the perspective of reviewers) are not in any way standardized when it comes to the relation between the objective reading of the manuscript (in the comments for authors) and the recommendation. And obviously the question about where to set the bar for acceptance of an article, where to set the bar for an $\mathrm{R} \& \mathrm{R}$ - these are questions that can only be answered well by the editor or editors themselves, who see the entire swath of submitted manuscripts and therefore have a much stronger grasp of what the standards are for this particular journal. It is also a simple but important fact that some reviewers are harsher in their comments and more generous in their recommendations, and vice versa. The editor's job is to consider a reviewer's recommendation, but at the same time to look past that recommendation to the objective evaluation of the manuscript in light of the journal's overall standards. 
In making final judgements I try to uphold two principles: first, I always seek to avoid going strongly against the judgement of a reviewer, and second, I always want to be as fair to the author as possible. Needless to say, in reading close to 2000 reviews over the past five years there have been many occasions in practice when these two principles conflict, when to follow the first principle I would have had to violate the second. I have done everything in my power to limit those occasions of conflict, but when they occur I always uphold the second principle at the expense of the first. I should note here, however, that in the many, many cases where the two reviewers agree, I have never gone against the judgement of the reviewers. Whenever two reviews have made the case for reject, I have rejected; whenever two reviews have made the case for $R \& R$, I have $R \& R$ 'd. When reviews are split, matters grow more complicated, and I have developed a variety of techniques to deal with them. Sometimes, of course, the split is only apparent: for example, both reviews make a damning critique of the piece, but one reviewer recommends reject and the other recommends $R \& R$. Under these cases I am not violating the first principle by rejecting the article, because my decision is based on the substance of the reviewer's work. (And this example illustrates quite forcefully why decision recommendations from reviewers are taken as confidential suggestions to the editor.) But at times splits are more than superficially apparent - sometimes they are very much real. In these cases I sometimes solicit a third review; I sometimes have an associate editor review the manuscript; but in all cases of split reviews I read the manuscript extremely closely myself and bring my own judgement to bear on the decision. Whatever the result, I try to explain the decision to the author in even greater detail, and on some occasions I have also written to reviewers to let them know that my decision went against their own judgement. (Writing to reviewers is not, however, a matter of $C P T$ policy, as we simply do not have the time to add this to our list of labors.)

\section{Editorial Ethos, 2010-2015}

The above practices were informed by my overall intuitive sense of how best to "edit a journal' and certainly by what I inherited when taking over submissions at $C P T-$ 'what I inherited' includes both the processes and structures in place, and also the aims, scope and mission as articulated at the beginning and carried out for almost a decade by the founding editors. It seemed to me that the most distinctive mark of $C P T$, and the element that I most wanted to carry on in my time as submissions editor, was that CPT published the best work in political theory no matter where that material emerged. $C P T$ published work then and now in: continental theory, analytic political philosophy, feminist theory, post-colonial theory, post-structuralism, deliberative democracy, queer theory, comparative political theory, radical democracy, cultural studies, international political theory, and the list could and should go on and on to include inter- and anti-disciplinary work that cannot be named in any pre-given 
list of categories. Who on earth could be 'the expert' or even 'an expert' in all of those fields simultaneously? Not I - not then and not now.

At the very moment of becoming editor I felt palpably that in order not to simply publish 'stuff I like' or things written in and by my network of close colleagues and friends in political theory, I would have to actively work to avoid doing so. Thus, the second major architectural move that Terrell and I made, after creating the wall to separate 'Articles' from everything else, was to bring on board a team of associate editors from a wide variety of fields and areas in political theory, and from a diverse group of institutions and geographies, all of whom would help to form a much broader and deeper domain of expertise. Especially in the early days of running submissions, I simply could not have done my job without the help, support, consultation and hard work of that initial group of associates, ${ }^{6}$ and over the years I continued to work with and through the associates, ${ }^{7}$ who were always the ones that, in my mind, created the conditions of possibility for me to attempt to publish the best in political theory, no matter the area. ${ }^{8}$

In addition to these structural changes, over the years I started to develop a more substantive and coherent editorial philosophy, and in describing this model to colleagues, reviewers and authors I found that it was, as is so commonly the case with political theorists, easier to describe my approach to running submissions by way of contrast with a different approach. I call that other approach the 'curation model' of editing and publishing, and as I have discussed my editorial work with colleagues and especially with other editors, I have been struck by how common this curation model is - in terms both of the practices of journals and the philosophy of journal editors. In other words, 'curation' is not merely a denigrated other, and it is not even an ideal type; many journals explicitly, to lesser or greater degrees, operate on a curation model.

As I see it, in editing as curating, the goal of an editor is to pick and choose the material that she or he wants to highlight and bring to the field, to support the best writing and research done in that area and to endeavor to make such work more viable in, and important to, the field of political theory. This means, of course, that editors believe the material they publish is outstanding and worthy of publication, but the process by which they select what material to publish and what not to publish the main job of an editor is to say 'no' - centrally involves giving higher consideration to certain types of work in political theory over other types of work. Maybe this is because the editor relates more to those types of work (perhaps it is the sort of work he or she does); maybe it is because the editor simply sees certain types of work as more important to the field than others; or maybe it is because the relatively narrow range of reviewers the editor calls on tend to agree on what types of work count as most important.

Regardless of the precise parameters, we can see clear examples of curation in specialist journals, and also in those journals that operate on the basis of an editorial collective, one which makes all decisions jointly, that vets most articles internally, 
and that explicitly holds a focused (often narrow) conception of the subject matter they publish. Anyone who has received a reject decision from a journal wherein the editor faults the author for failure to cite the members of the small editorial board has bumped into the curation model. But the idea of editing as curating operates much more broadly than this, and can even be seen (in different, perhaps more diffuse, form) in journals otherwise understood to be generalist journals, but which take on a different flavor or approach based on who is in charge of submissions. Lest there be any confusion, I want to stress here something that I cannot assert strongly enough: the curation model is surely a viable and coherent model, and many readers may even see it as a superior model to the one I am beginning to describe. Moreover, some degree of 'curation' is inherent to the very practice of editing.

My aim here is not to offer a critique of curation, but merely to give an account of my own approach to editing as an alternative to curation. Over and over again, I have been guided by an effort to avoid curating, and thus in many ways my editorial philosophy has emerged by repeatedly seeking to distinguish what I do as an editor from what a curator would do. ${ }^{9}$ Regardless of the potential strengths of a curation model of editing, I insist that such is not the only model of running submissions.

And there are dangerous potential tendencies built into the curation model, since, at a certain extreme, editing a journal in this way can reduce to 'publishing work that you like and work that your colleagues and friends like'. My goal when taking over submissions at $C P T$ was to avoid precisely that result; my aim was to publish the best work in political theory, across the entirety of the field, regardless of whether it was material that would be at the top of my own reading list. And early on I realized that there is a certain gravitational pull of the curation model: it is easier to curate because doing so allows you to call on your own expertise in the field more frequently, and to more easily tap into your established networks for reviewers.

Therefore, much of the architecture of the journal and many of the procedures and principles that I have described above were implemented in an effort to push back against that pull toward curation. First of all, special issues and symposia offer an obvious place where a curated model of editing can easily flourish. By designating significant percentages of the journal output to particular areas, and by diminishing the rigors of the review process for manuscripts that are a part of those areas (which, as I described above, is simply what has to happen in order for special issues and symposia to hang together properly), a journal can focus its output in important ways, and dramatically reduce the chances that certain material will make it into the journal. If, for example, a journal never publishes special issues on Rawls and Habermas, but does publish special issues on Agamben and Adorno, then authors working in the former areas simply have a much longer shot of getting their work accepted at the journal.

Editing as curation can also manifest itself in more generic aspects of the journal's submissions process. We can see this with the idea of 'fit' that I discussed above. A curation model would depend upon a strong vision of what counts as proper 
content for a journal, and would then reject a large number of manuscripts for lack of 'fit'. In this way, editing-through-curation would lead to a very high internal rejection rate; that high internal reject rate would prove essential to the journal's structure. If many manuscripts are rejected for lack of fit, and many others never get past the editor's desk, then it is already possible to have narrowed the scope of the journal enough so that only manuscripts that the editor sees as important, interesting, provocative, or relevant are going out for review. Internal rejections, if used frequently enough, can make it possible for even the most 'generalist' journal to operate with a strong ethos of curation. As I alluded to above, the other well-known secret of journal editorial processes is that a journal's internal rejection rate has a profound impact on the very meaning of 'blind peer review'. The higher the internal rejection rate, the more overall control of review process is held by the submissions editor.

But perhaps one can redescribe this phenomenon in more powerful terms by flipping things around: in order to avoid curation, one has to make an active effort to avoid using either 'fit' or the internal review process as mechanisms to narrow the scope of what a journal publishes. Here, perhaps, the point can be conveyed most clearly by being very honest about the fact that every member of the field of political theory sees certain areas of that field as more productive, viable and important than others. No one working in contemporary theory today is agnostic about which authors, which schools, which approaches are the best ones. No one honestly believes that work on Nozick and work on Balibar are equally relevant. And a journal editor is nothing other than a member of the field. As I saw it when I first took over submissions at $C P T$, and as I still see it now, the only way to avoid curation is to admit to oneself this basic fact - only then can an editor figure out how to work against it.

This means that as an editor, I need to give a larger benefit of the doubt to work in fields I do not know well. If we receive a manuscript on Rancière, I can feel confident in my own judgement about whether or not the piece has the possibility to make a contribution to the field of contemporary theory widely conceived, to speak beyond narrow debates that would only be of interest to specialists. I can make this judgement because in this case I am one of those specialists. But if we receive a manuscript on Schelling, it will be much harder for me to tell if the piece is doing novel and important work on Schelling that also contributes to wider debates. To treat the Schelling manuscript fairly, I may need to call in the judgment of an associate editor before deciding whether to reject internally or send out for external review; indeed, in some cases I might be slightly more likely to send out a piece for external review if it is outside of the band of 'stuff I know and like', and the reason is quite simply that I am making a conscious effort to balance out my own particular interests and preferences for the benefit of the wider audience of $C P T$. In other words, I do not expect $C P T$ 's readers to share my set of interests in political theory, and I want what we publish in $C P T$ to speak as forcefully as possible to as wide an audience as we can imagine. Put more crudely: over the years it has not been 
uncommon for us to publish articles that I myself was not personally that interested in. But I never published an article that I was not certain met the most rigorous standards and reached the very high bar for publication as a peer-reviewed piece; and it was not uncommon for one of the articles that did not excite me all that much to wind up as one of the most downloaded, most cited, or simply most talked-about articles we put out. As editor, I take my greatest pride in cases like this.

Taking a wider view of things while looking back over the past five years, what we might call my 'non-curated' model of editing is not so much an editorial philosophy as an animating ethos, not so much a mission statement as a structural approach, not at all a strict set of rules, but a kind of guiding light that helped me to make decisions, to choose one path rather than another. To repeat: I am not suggesting that every journal's submissions ought to be run this way, but I do think that for a generalist journal that aspires to be open to submissions from a wide variety of subfields, there is a certain coherence and integrity to running submissions as an effort to publish the best no matter where it comes from.

Let me close this section by noting a very important relationship between submissions policies at journals and the current state of the field. My choice to always work against curation comes partially from a certain professional and ethical burden that came with the job of running submissions. I felt this burden most forcefully vis-à-vis the hundreds upon hundreds of submissions that we received over the years from junior scholars - both those lucky enough to be on some sort of permanent or tenure track and those still hoping to achieve precisely that goal. For all of these junior scholars the competition to place articles in peer-reviewed journals is fiercer than it has ever been, and the stakes for publishing are as high as they have ever been. Most readers already know that in the field of political theory today merely getting a job often requires having just the sort of record that 20 years ago would have easily gotten one tenure. With fewer and fewer jobs combined with greater and greater emphasis on peer-reviewed journal articles (and university press books) as prerequisites to get those jobs, the journal submissions editor necessarily becomes something of a custodian over a public good for the entire field. In that context, it seems to me that merely to publish the material that I like is to do a great disservice to the field. In contrast, running submissions on a non-curation model has looked to me like not only an intelligible and fecund way to run the journal for its own sake, but also a viable ethical response to the overall state of the discipline.

\section{CPT's Next Editorial Transition, 2016-}

The above all amounts to a prologue for announcing the structural rearrangement of the submissions process here at $C P T$. After half a decade of running submissions solo, ${ }^{10}$ and after watching $C P T$ 's overall submissions numbers double over that period, I thought that it was time to bring in fresh eyes, fresh voices, and new perspectives, to 
renew the reserves of energy that are required to oversee the article review process. Indeed, avoiding curation may require more frequent editorial refreshes. At the same time, Terrell and I both felt that we were not quite finished with our overall tenure as stewards of the journal, and that we would like to continue our work at the helm for another term. Therefore, in early 2015 we put together a plan for restructuring $C P T$ submissions according to a team model. We then began to implement and test that new model in the middle of the year, and by late 2015 (as the website lineup and masthead list noted) we had transitioned to this new submissions process.

Under our new model submissions are run by a team of six editors, which in addition to myself and Terrell, includes: Lisa Disch, Michaele Ferguson, James Martin and Andrew Valls. Our overall editorial lineup is completed by Lori Marso who runs all Critical Exchanges and Andrew Schaap, who is in charge of book reviews. Our basic submissions practices and principles, as I detailed them above, have not changed in any substantive ways: all of our general instructions for authors are the same, so our basic approach has been to implement a team model that largely carries on the submissions process in the same way I had done over the past five years. It goes without saying, of course, that some small changes have had to be made on the back end in order to put the team model in place. Susanna Siddiqui receives all submissions and communicates directly with authors and reviewers. Terrell coordinates the team of editors by dividing up submitted manuscripts; each editor then runs each review individually (whether internal or external) from initial submission to final decision. The team model creates certain logistical complexities, but at the same time it generates an important resource in that each editor has the other members of the team to call on for reviewer advice, outside perspective and second or third opinions/judgements.

I want to emphasize, however, that the move to a team model is not itself a shift toward a curated model of editing $C P T$. Quite the contrary - much of the clarity in my vision of a non-curated editorial ethos has come about through discussions with the new editors and through our efforts to implement the team model as a non-curated approach to editing. We see the new model as expanding our editorial areas of expertise and thus making it possible to reach an even wider swath of work in the broad and interdisciplinary field of contemporary political theory. But unlike some editorial collectives (who make substantive judgements, as a collective, on each manuscript submitted) our team model involves coordination of individual editors, each of whom runs and oversees a review process that relies on the judgement of external reviewers to help us locate the very best work across all areas in the field - not just the areas that any one editor knows or works in, nor even the aggregate of the various areas that we all know and work in. Our collective knowledge and wisdom has grown since moving to the team model, but we do not intend to publish material only in the areas we know well. We will continue in our efforts to uphold the very highest standard for thoroughly rigorous and field-transforming research and writing, while we also hold the line in resisting any a priori circumscription of what counts as such. 


\section{Notes}

1 Of course my approach to submissions proves much clearer to me now than when I started, and it seems to me that an organic, developing approach to the submissions process may be superior, other things being equal, to any attempt to have an ethos or philosophy that would drive the practices. Running a journal is a complex, messy business, involving the coordination of literally hundreds of strongly independent, and always unpaid, scholars. There is no such thing as clear-cut and direct implementation of principles into practice. There can always and only be a flexible and shifting ethos that guides decisions and allows de facto policies to emerge. Put simply: I developed a lot of submissions rules in my time as submissions editor, and I still believe in the fundamental importance of these rules; at the same time, every rule has an exception, and in this case the exceptions are often at least as important as the rules.

2 There are also a number of articles that come in that fail to meet the basic requirements for submission, as detailed in our 'Instructions for authors' on our website; for example they have issues regarding word count, English language, anonymity and so on. These manuscripts are 'returned to author' and often come back to us in the proper format; those that do not come back are not counted as manuscripts reviewed and are not a part of our overall reject category.

3 This simple but essential point opens on to a much wider discussion, one well beyond the scope of this editorial, about the current status of 'review work' and the situation of reviewers in a variety of fields across the humanities and social sciences. One recent article has framed this broad issue in terms of the problem of 'reviewer fatigue', asking the basic yet important question 'why scholars decline to review' (Breuning et al., 2015, p. 595). The article produces some interesting data on response rates to requests for review and reasons given for declining to review, but it perhaps proves most interesting for what it leaves out. In some ways the project is conducted as if in a vacuum. Hence, the authors say nothing at all about the current neoliberal transformation of the university, in which more and more journals are being bought by larger corporations and run on a profit-maximizing model. We all know that journal work (both reviewing and editing) has never been remunerated, but at least to some extent there was a time in the past when more of that work was done for journals that were owned by non-profit entities. To many, the extraction of profit from journal titles, based on hundreds upon hundreds of hours of uncompensated labor, looks like a real problem. (To others, of course, corporate backing of journals looks necessary to sustain important intellectual work in a time when other support is sorely lacking.) In any case, the authors of the above study do not even mention one reason now sometimes given for declining to review - namely, the specifically political refusal to offer free labor to any journal owned by a for-profit corporation. This sort of response to an invitation does not happen often, but it does happen, and increasingly so. Finally, despite focusing on the US context, Breuning et al. say absolutely nothing about the adjunctification of higher education. But we all know that the percentage of faculty in permanent positions (tenured or tenure track, in the United States) has been steadily going down for years and years, all while the pool of adjuncts and term appointments grows. The math is thus very simple: we have more and more people who desperately need to submit to journals and produce peerreviewed work, but fewer and fewer people available to review. Indeed, when one also considers the greater reluctance on the part of some senior scholars to review at all, the burden placed on those midcareer scholars in secure positions proves even higher still. As an editor, I ask for the help of these individuals over and over again; their work lies at the heart of any journal. I say it again: cherish thy reviewers.

4 This paragraph captures something of the signature of $C P T$ in our approach to political theory. It therefore applies to every stage of the review process: the failure of a piece to be able to speak to the field broadly may well be one reason given for an internal reject, but the insistence that a piece widen itself even further will also often appear as a requirement of an $R \& R$ 'd manuscript or even as a final needed change for an accepted manuscript. 
5 In 2015, of course, it is impossible to prevent reviewers from trying to discover the identity of an author, but we strongly discourage reviewers from doing so. If a reviewer knows the identity of an author, he or she should let the editors know and will quite likely be taken off the review. If a reviewer has read the work before, or is a close colleague or friend of the author, then he or she is obligated to let us know and we will find another reviewer.

6 I offer my deepest and heartfelt appreciation to the original associates who agreed to come on board before they, or I, really knew what that would mean: Jeanne Morefield, the late Joel Olson, Robert Watkins and Karen Zivi.

7 I am also indebted to associates who have come and gone over the past five and a half years: Daniel Butt and Alex Lefebvre. And a special thanks to one associate whom I relied upon so heavily that he was also a first choice to serve on the new team of editors: Andrew Valls.

8 Our current lineup of associate editors remains a crucial element in the day-to-day functioning of the journal, and I would like to take a quick moment to thank them here for all their important hard work: Elisabeth Anker, Alan Finlayson, Ben Golder, Leigh Jenco, Alex Livingston and Holloway Sparks.

9 My own way of editing is to avoid curating, but that does not mean that other editors cannot or should not curate, nor that they cannot curate well, nor that editing by way of curating cannot make an important contribution to the field. Indeed, editing by curation may well shape and impact the field much more than my alternative approach, and for that reason it could easily be seen as superior. In a period in which the number of journal titles is rising and the number of submissions to all journals is also rising, I can easily see the attraction of carving out a space for particular brands or flavors of work and seeking to foster, encourage, and cultivate that work. Moreover, if a subfield of political theory is felt to be underrepresented, then perhaps curation may a viable model for overcoming such a problem.

10 Over those five years I was the sole editor in charge of submissions, but I absolutely could not, and did not, do that job alone. I am deeply grateful for the professionalism, dedication, and extremely hard work of my two assistant editors, Drew Walker and Tripp Rebrovick. Anything that I did well as an editor was made possible by the amazing work accomplished by both Drew and Tripp, by the fact that they responsibly took care of so many daily details that I could focus on other, important matters. I would also like to thank the Department of Political Science at Johns Hopkins, especially the chairs over those years, Jane Bennett, Dick Katz and Adam Sheingate, who have been strong supporters of my work on the journal and who see it as a great benefit to both our graduate program here at Hopkins and to the intellectual life of the department. Last but by no means least, while I was in charge of submissions, Terrell and I have been truly co-editors from day one, and everything I did on the side of submissions was made possible by his work in so many other areas of the journal, by his continuous consultations, and his unflagging support. Everyone should be so lucky as to have such a true collaborator. I am grateful to Terrell for bringing me on in the first place, and for so much more before and since.

\section{References}

Browning, G., Hutchings, K. and Prokhovnik, R. (2002) Editorial. Contemporary Political Theory 1(1): 1-2. Breuning, M., Backstrom, J., Brannon, J., Gross, B.I. and Widmeier, M. (2015) Reviewer fatigue? Why scholars decline to review their peers' work. PS: Political Science \& Politics 48(4): 595-600.

Samuel A. Chambers

Johns Hopkins University, Baltimore 21218, USA E-mail: samchambers@jhu.edu 